\title{
THE CARDIAC OUTPUT AND OTHER MEASUREMENTS OF THE CIRCULATION IN COARCTATION OF THE AORTA ${ }^{1}$
}

\author{
By HAROLD J. STEWART AND ROBERT L. BAILEY, JR. \\ (From the New York Hospital and Department of Medicine, Cornell University \\ Medical College, New York)
}

(Received for publication September 19, 1940)

The clinical diagnosis of coarctation of the aorta has been made during life with increasing frequency in the past few years. This defect has taken on increased significance recently due to attempts to explain the hypertension associated with it on the basis of renal ischemia of the Goldblatt pattern. The effect of this congenital defect on the circulation has been studied, however, in only a few patients. Blumgart, Lawrence, and Ernstene (1) reported detailed observations on two patients. The difference between the oxygen contents of the arterial and venous blood of both the arms and the legs was within normal limits. There was delay in the femoral pulse and rounding of the pulse wave. Measurement of the velocity of blood flow gave evidence of slowing of the arterial blood flow in the lower extremities.

Measurements of cardiac output are available in only four cases. Grollman and Ferrigan (2) found a normal arteriovenous oxygen difference, an increased oxygen consumption, and elevated cardiac output in one case. ${ }^{2}$ Strayhorn (3), who made observations of a pregnant woman, ${ }^{3}$ found the arteriovenous oxygen difference normal and the oxygen consumption and cardiac output increased. Following delivery, the oxygen consumption, cardiac output, and arteriovenous oxygen difference were all normal. Stewart and others (4) studied the dynamics of the circulation in one case. ${ }^{4}$ Lequime (5) found a normal arteriovenous oxygen difference and basal metabolic rate, and a cardiac output of 3.44 liters per minute in one case.

1 Read by title before the Fifty-Fifth Annual Meeting of the Association of American Physicians, held in Atlantic City, New Jersey, May 8, 1940.

2 This patient was later seen in New York Hospital and is Case 4 in our series.

8 This patient was seen in New York Hospital and is Case 14 in our series.

4 This patient was seen in New York Hospital and is Case 4 in this paper.
Our studies were made on fourteen patients suffering from coarctation of the aorta who were seen in the New York Hospital during the last seven years. ${ }^{5}$ In thirteen the diagnosis was made during life; in one the diagnosis was revealed at autopsy; in four of the thirteen cases the diagnosis was confirmed at autopsy. All subjects showed normal sinus mechanism. Clinical data on these fourteen cases are presented in Table I. On physical examination there were no clinical evidences of other cardiac anomalies which might, through recirculation of blood, give rise to erroneous results in the measurements.

\section{METHODS}

All observations were made in the morning under basal conditions. Measurements of the cardiac output were made by the acetylene method, three samples of gas being taken as first recommended by Grollman (6), and as further elaborated by Grollman and others (7). Our method and the order of the procedures are exactly as we have already described (8). The following data were also collected: Oxygen consumption, vital capacity, height and weight, electrocardiograms with IVF chest leads $(9)$, venous pressure $(8,10)$, blood pressures in both arms and both legs, two-meter $x$-ray photographs of the heart for measurement of the cardiac area (11), and cardiac volume (12).

The arm-to-tongue circulation time was estimated by the use of Decholin $(8,13)$. In certain patients (Cases $2,5,7,8$, and 9), Mascosol ${ }^{6}$ (14) was used. In them the time was measured from the beginning of the injection until the patient perceived a flash of heat in the throat, perineum, hands, and feet. The inhalation of $\mathrm{CO}_{2}$ was used to estimate circulation time from the lungs to the respiratory center in seven patients (15) (Table II).

$5 \mathrm{We}$ are indebted to Dr. J. M. Steele for referring Cases 2 and 5 to us. They are Cases A. C. and W. G. in his paper (22).

- Mascosol, a solution described by Spier, Wright, and Saylor (14) containing magnesium sulphate, calcium gluconate, and sodium chloride, was supplied to us for these studies by The Nepera Chemical Co., Inc., of Yonkers, N. Y. 


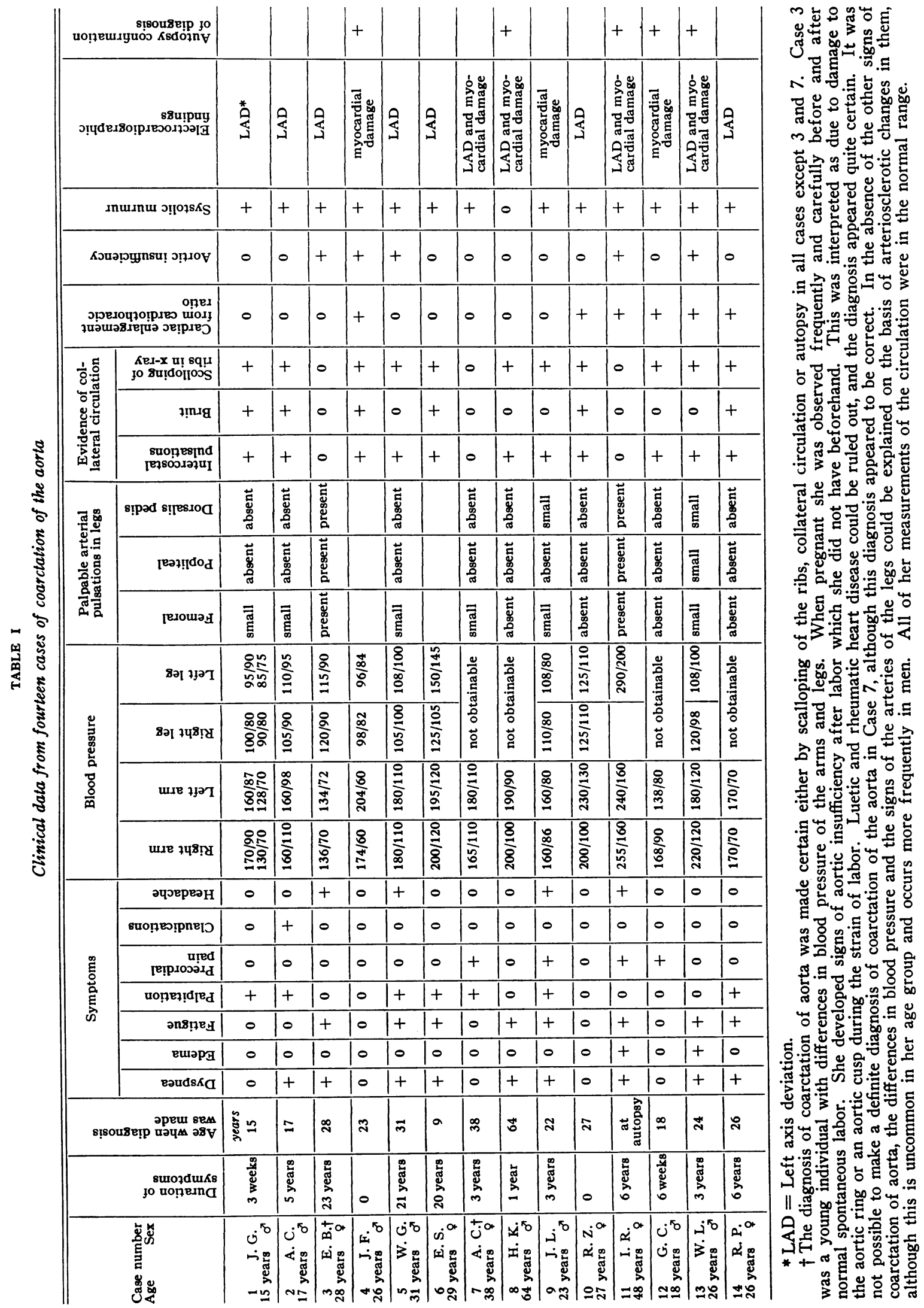


TABLE II

Data relating to the circulation of nine cases of coarctation of the aorta*

\begin{tabular}{|c|c|c|c|c|c|c|c|c|c|c|c|c|c|c|c|c|c|c|c|c|c|}
\hline 总葛 & 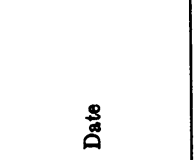 & 㔛 & 宽 & 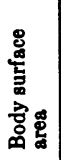 & . & 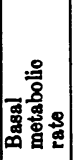 & 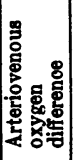 & 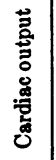 & 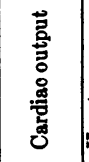 & 窟 & 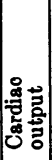 & 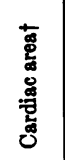 & 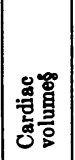 & 产 & 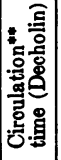 & 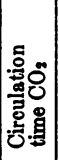 & 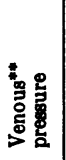 & 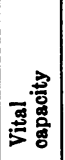 & $\begin{array}{l}\frac{0}{9} \\
\stackrel{0}{0} \\
\frac{0}{0} \\
\frac{8}{8}\end{array}$ & 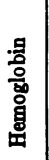 & 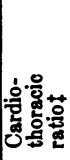 \\
\hline $\begin{array}{c}\text { Average } \\
\text { normal } \\
\text { values\$8 }\end{array}$ & & $\mathrm{cm}$. & kgm. & $\approx q . m$. & $\begin{array}{c}c c . \\
\text { per } \\
\text { min- } \\
\text { ute }\end{array}$ & $\begin{array}{l}\text { per } \\
\text { cent }\end{array}$ & $\begin{array}{c}c c . \\
61.5\end{array}$ & $\begin{array}{c}\text { liter } \\
\text { per } \\
\text { min- } \\
\text { ute }\end{array}$ & $\begin{array}{c}\text { liters per } \\
\text { q. } m . \\
\text { per } \\
\text { minute } \\
2.09\end{array}$ & $\begin{array}{c}\text { per } \\
\text { min- } \\
\text { ute }\end{array}$ & $\begin{array}{c}c c . \\
\text { per } \\
\text { beat } \\
59\end{array}$ & $2 q . \mathrm{cm}$. & $c e$. & $\begin{array}{c}\text { gm.m. } m . \\
\text { per } \\
\text { beat }\end{array}$ & $\begin{array}{c}\text { sec- } \\
\text { onds } \\
14.4\end{array}$ & $\begin{array}{l}\text { sec- } \\
\text { onds }\end{array}$ & $\begin{array}{c}\underset{\substack{\operatorname{mm} . \\
\text { saline }}}{ } \\
101\end{array}$ & $c c$. & $\begin{array}{c}\text { million } \\
\text { per } \\
\text { eu } m m .\end{array}$ & $\begin{array}{l}\text { per } \\
\text { cent }\end{array}$ & $\begin{array}{l}\text { per } \\
\text { cent }\end{array}$ \\
\hline 1 & $\begin{array}{lr}\text { June } & 15,1938 \\
\text { September } & 15,1939\end{array}$ & $\begin{array}{l}175.0 \\
181.0\end{array}$ & $\begin{array}{l}51.0 \\
59.9\end{array}$ & $\begin{array}{l}1.62 \\
1.78\end{array}$ & $\begin{array}{l}241 \\
272\end{array}$ & $\begin{array}{l}-6 \\
-3\end{array}$ & $\begin{array}{l}43.3 \\
44.6\end{array}$ & $\begin{array}{l}5.59 \\
6.09\end{array}$ & $\begin{array}{l}3.45 \\
3.42\end{array}$ & $\begin{array}{r}108 \\
80\end{array}$ & $\begin{array}{l}52 \\
76\end{array}$ & $\begin{array}{l}100.2 \\
122.3\end{array}$ & $\begin{array}{l}485.0 \\
654.6\end{array}$ & $\begin{array}{r}84.9 \\
103.4\end{array}$ & $\begin{array}{r}10.6 \\
9.9\end{array}$ & $\begin{array}{l}5.0 \\
6.2\end{array}$ & $\begin{array}{l}117 \\
118\end{array}$ & $\begin{array}{l}3500 \\
4000\end{array}$ & 4.3 & 90 & $\begin{array}{l}42 \\
41\end{array}$ \\
\hline 2 & February 6,1940 & 180.0 & 66.8 & 1.84 & 307 & +5 & 49.6 & 6.19 & 3.36 & 68 & 91 & 132.3 & 733.5 & 163.4 & 13.5 & 4.8 & 50 & 5300 & 5.0 & 100 & 44 \\
\hline 3 & January 17,1940 & 167.3 & 60.4 & 1.67 & 201 & -4 & 61.7 & 3.26 & 1.95 & 60 & 54 & 110.2 & 531.8 & 80.8 & 14.1 & 6.7 & 72 & 2800 & 4.7 & 100 & 49 \\
\hline 4 & March $\quad 30,1935$ & 179.0 & 66.5 & 1.82 & 315 & +24 & 90.3 & 3.52 & 1.93 & 89 & 41 & 284.2 & 2196.9 & 69.7 & 16.4 & & 88 & 3250 & & & 59 \\
\hline 5 & September 23, 1939 & 165.0 & 48.3 & 1.52 & 257 & +25 & 59.3 & 4.33 & 2.85 & 96 & 45 & 127.8 & 698.0 & 82.6 & 14.5 & & 99 & 4100 & 5.5 & 116 & 45 \\
\hline 6 & September 30, 1939 & 156.7 & 52.2 & 1.50 & 218 & +17 & 47.1 & 4.63 & 3.09 & 96 & 48 & 87.0 & 392.2 & 105.4 & 10.7 & 6.5 & 67 & 2700 & 5.1 & 102 & 44 \\
\hline 7 & January 30,1940 & 152.5 & 54.8 & 1.51 & 172 & -8 & 54.3 & 3.17 & 2.10 & 70 & 45 & 106.4 & 530.0 & 85.1 & 11.2 & 9.3 & 66 & 2300 & 4.6 & 100 & 49 \\
\hline 8 & December 29, 1939 & 183.0 & 74.6 & 1.97 & 224 & -7 & 65.2 & 3.44 & 1.25 & 80 & 43 & 143.5 & 829.5 & 76.6 & 16.8 & 10.8 & 43 & 5100 & 4.0 & 94 & 46 \\
\hline 9 & March $\quad 19,1940$ & 181.5 & 69.3 & 1.91 & 216 & -20 & 70.0 & 3.07 & 1.61 & 68 & 45 & 128.0 & 700.0 & 71.6 & 18.6 & 6.5 & 88 & 4400 & 5.5 & 115 & 46 \\
\hline
\end{tabular}

* See blood pressure records which go with these observations in Table I.

+ The areas of the heart in Cases $10,12,13$ and 14 were $83.5,173.2,174.2$, and 128.1 sq. cm., respectively.

\$ The volumes of the hearts in Cases $10,12,13$ and 14 were $370.0,1101.3,1111.9$ and 701.2 cc., respectively.

** The circulation time and venous pressure were 9.7 seconds and $104 \mathrm{~mm}$., respectively, in Case 10 .

$\ddagger$ The cardiothoracic ratios in Cases $10,12,13$ and 14 were 54,59,60, and 55, respectively.

$\$ \&$ Stewart and Watson ((16) Tables II and III).

\section{OBSERVATIONS}

The cardiac output was measured in nine (Cases 1 to 9 ) of the fourteen patients. In one of these (Case 1) observations were made on two occasions. None of these patients exhibited signs or symptoms of congestive heart failure. The data are recorded in Table II.

The cardiac output per square meter of body surface per minute (cardiac index) was increased in four cases (Cases 1, 2, 5, and 6) in whom the range was from 2.85 to 3.45 liters; it was within normal limits in four cases (Cases 3, 4, 7, and 8) with a range from 1.93 to 2.10 liters, and was reduced in one patient (Case 9) to 1.61 liters. The range of basal heart rate was from 68 to 108 beats per minute. The cardiac output per beat ranged from $41 \mathrm{cc}$. to $54 \mathrm{cc}$. in all but two cases. Case 2 had an output of $91 \mathrm{cc}$. per beat and Case 1, on the second estimation, fifteen months after the earlier one, had an output of $76 \mathrm{cc}$. per beat. During this interval there had been a gain in weight and in height, giving rise to an increase in surface area from 1.62 to $1.78 \mathrm{sq}$. m. The oxygen consumption increased slightly at the time of the second estimation but the basal metabolic rate was unchanged ( 6 per cent and 3 per cent, respectively). Both the arteriovenous oxygen difference and the cardiac index were unchanged.

In three of the nine patients the basal metabolic rate was increased to +24 per cent (Case 4 ), +25 per cent (Case 5 ), and +17 per cent (Case $6)$; in one it was decreased to -20 per cent (Case 9); and in the remaining five patients (Cases 1, 2, 3, 7, and 8) it was within the normal range.

In four (Cases $3,5,7$, and 8 ) of the nine cases the arteriovenous oxygen difference was within the normal range $(60.0 \pm 5.0),{ }^{7}$ in three (Cases 1,2 , and 6) it was decreased, and in two (Cases 4 and 9) it was increased.

According to x-ray photographs, the heart was increased in size with a cardiothoracic ratio of over 50 per cent in only one of the nine patients having measurements of cardiac output, and in

7 Stewart and Watson (16) studied normal individuals under the same conditions and by the same methods. 

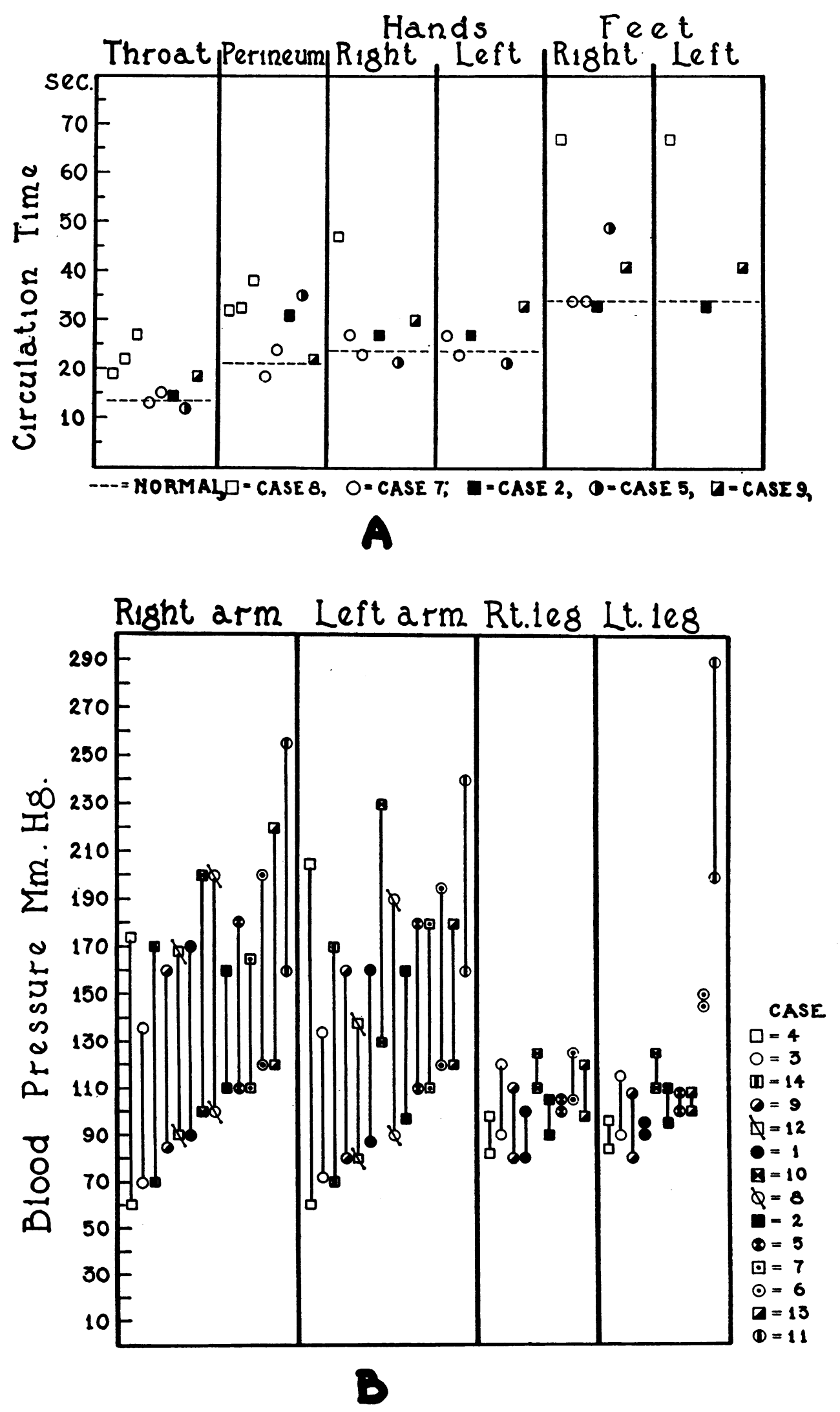

FIG. 1 
four of the other five patients (Table II). The left ventricular work ranged between 71.6 and 163.4 in grammeters per beat. When plotted against the heart size, the left ventricular work per beat was found to be adequate in all except Case 4 whose heart was large and in whom the cardiothoracic ratio was 59 per cent.

The arm-to-tongue circulation time (Decholin) was within normal limits (10.4 to 17 seconds (16)) in seven of the nine patients. In Case 10 it was slightly shorter than normal, measuring 9.7 seconds; and in Case 9 it was slightly prolonged, measuring 18.6 seconds. One patient (Case 8) had a prolonged circulation time throughout the parts of the vascular tree which were tested by Mascosol: throat, hands, perineum and feet (Figure 1A). In the other four cases (Cases 2, 5,7 , and 9) the arm-to-throat time was within or near normal limits. The arm-to-hand time was moderately prolonged in Case 9; the arm-toperineum time was definitely proloned in Cases 2 and 5 ; and the arm-to-foot time was prolonged in Cases 5 and 9.

The velocity of the blood flow from the lungs to the respiratory center was within or near normal limits in seven cases (Table II).

The venous pressure was slightly elevated in Case 1 and normal in the others (Table II).

\section{DISCUSSION}

The cardiac index was within the normal range or increased in all except one patient in whom it was decreased. The increased cardiac index in the two younger patients (Case 1 and Case 2) aged 15 and 17 years, respectively, is probably normal for their age (16). In them the basal metabolic rates were normal, and arteriovenous oxygen differences were small. In Case 5, having an increased cardiac index, the oxygen consumption was increased, and in Case 6 not only was the oxygen consumption increased, but the arteriovenous oxygen difference was small. In Case 9, having a decreased cardiac index, the basal metabolic rate was low and the arteriovenous oxygen difference was wide. In this case also the arm-to-tongue circulation time was slightly longer than in the other patients (Figure 1A). In Cases 3, 7, and 8, having normal cardiac indices, both basal metabolic rates and arteriovenous oxygen differences were normal. In a fourth patient, Case 4, having a normal cardiac index, the basal metabolic rate and arteriovenous oxygen difference were both increased. This patient also exhibited increased basal metabolic rate when he was studied by Grollman and Ferrigan (2), but the arteriovenous oxygen difference was then normal. He died a few months after our observations were made (18); the increased arteriovenous oxygen difference no doubt indicated decrease in functional capacity of the heart $(4,19)$. The basal metabolic rate was increased in three of the nine patients. Grollman and Ferrigan (2) suggested that this phenomenon was occasioned by the increased blood supply to the thyroid gland. In none of the patients having increased oxygen consumption, however, was the circulation time shortened as is the case in hyperthyroidism.

In all except one (Case 4) of the nine cases, the heart at rest maintained an adequate output per beat in relation to its size. The cardiac output, as was discussed above, was within normal limits in this patient but the heart was greatly enlarged, and as a consequence the output was not in proportion to the cardiac size.

The velocity of blood flow was measured by three methods. To points above the level of coarctation it was within or near normal limits (Table II). The values of the arm-to-perineum and arm-to-foot circulation time with the solution described by Spier, Wright and Saylor (14) were prolonged in most instances but normal in a few cases (Figure 1A). Prolongation of the circulation time to the feet in a patient with normal circulation time to the throat and upper extremities is indicative of the devious route which blood must take in reaching the lower extremities. It may be recalled that Blumgart, Lawrence, and Ernstene (1), and, more recently, Woodbury, Mur-

Fig. 1. Circulation Times and Blood Pressures in Conrctation of the Aorta

In Figure $1 \mathrm{~A}$ are recorded circulation times secured by using "Mascosol" in five patients suffering from coarctation of the aorta. The dotted lines show the average values for normal individuals. In Figure $1 \mathrm{~B}$ are recorded the blood pressures in the four extremities of fourteen patients suffering from coarctation of the aorta. 
phey and Hamilton (20) found delay in the pulse wave in the lower extremities, as well as a prolonged circulation time to the feet.

Disproportion of blood pressure in the arms and legs was the most striking and constant finding in this group of patients (Table I, Figure 1B). It is recalled that in normal subjects both the systolic and diastolic levels of blood pressure are higher in the legs than in the arms. All patients except Case 11 showed a higher systolic pressure in the arms than in the legs. The diagnosis was not made during life in this patient (Case 11) and at autopsy only slight narrowing was found at the site of coarctation. Hydronephrosis, secondary to occlusion of the right ureter, and arteriolar nephrosclerosis were found at autopsy and may explain the elevated arterial pressure in the absence of more marked constriction of the aorta.

In our cases the relationship of the diastolic pressures in the arms and in the legs was variable. Blood pressure levels could not be obtained in the legs in four patients. Of the remaining ten patients, three exhibited higher diastolic pressure in the legs, four had approximately the same diastolic pressures in the arms and legs, and three showed higher diastolic pressure in the arms.

King's (21) analysis of the blood pressure readings in the reported cases of coarctation revealed that the blood pressure of the arms may be within the normal range. This was the situation in Case 3 in our series; nevertheless the systolic pressure in the legs bore the usual relationship found in coarctation; namely, it was lower. King found the systolic pressure in one or both arms uniformly higher than that in the legs. He found diastolic pressures of a higher level in the legs than in the arms six times. In our cases the systolic blood pressure readings were higher in the arms than in the legs in all except Case 11. The diastolic pressure in the legs was higher than that in the arms in three cases and was above $90 \mathrm{~mm}$. in five cases. The levels of systolic and diastolic pressure in the arms and legs indicate that there is not only an increased resistance to the outflow of blood at the site of coarctation and in the collateral channels, but that there is a general increase in peripheral resistance sufficient to maintain a high diastolic pressure distal to the site of coarctation.
Steele (22) reviewed the knowledge of levels of arterial pressure in 203 cases of coarctation of the aorta and, by intra-arterial measurement, found the diastolic pressure to be elevated above $100 \mathrm{~mm} . \mathrm{Hg}$ in the femoral as well as the radial arteries in two of three cases he studied. $\mathrm{He}$ concluded that the increase in peripheral resistance need not be confined to the upper half of the body alone, that there may often be general increase in arteriolar tone throughout the body, and that, under these circumstances in so far as the distribution of peripheral arteriolar resistance is concerned, the arterial hypertension in coarctation of the aorta does not differ from the common forms of arterial hypertension. Our cases herein reported, in which the blood pressure in all extremities was increased, point to the same conclusion.

The absence of palpable pulsations in the arteries of the legs was an inconstant finding. Eight cases had palpable pulsations over the femoral arteries, and in four of these pulsations were also palpable over the popliteal and dorsalis pedis arteries. The pulsations were feeble, however. Pulsating superficial and intercostal arteries were palpable over the upper thorax posteriorly in eleven of the fourteen patients. In six of these, bruits were heard over the dilated arteries (Table I).

$\mathrm{X}$-ray examination of the chest revealed erosion of the ribs with scalloping and nicking of the inferior margins posteriorly in eleven of our fourteen cases, which was the most characteristic $x$-ray finding (Table I). Five cases showed defects in the aortic arch. This abnormality was not searched for in oblique films in all cases. One patient had absence of the aortic knob and one had a prominent aortic knob; both showed scalloping of the ribs.

Although these patients had hypertension and had performed an increased amount of work per beat over long periods, the heart, as ascertained from the cardiothoracic ratio, was enlarged in only one of the nine cases (Case 4) in whom the cardiac output was measured, and in four (Cases $10,12,13$, and 14) of the other cases studied; in the remaining one (Case 11) the film was misplaced before this measurement had been made. Four of the five cases having large hearts died during the seven-year period which these obser- 
vations covered. Enlargement of the heart, then, appears to indicate a poor prognosis.

Electrocardiograms did not show any pathognomonic changes. In eleven of the fourteen cases there was deviation of the electrical axis to the left, a finding which occasions no surprise because of burden placed on the left heart by the narrowing of the aorta and because of hypertension (Table I). In seven patients, the $\mathrm{T}$-waves of the electrocardiogram were abnormal and appeared to indicate myocardial damage. Since these studies were instituted, five of these seven have died. The occurrence of $T$-wave changes indicates a poor prognosis.

\section{SUMMARY AND CONCLUSIONS}

1. This study concerns fourteen cases of coarctation of the aorta. The diagnosis was made during life in thirteen of these, at autopsy in one case, and in four cases who died some time after the diagnosis had been made it was confirmed by autopsy.

The following observations were made in nine of these cases: cardiac output, basal metabolic rate, arteriovenous oxygen difference, cardiac output per beat, left ventricular work per beat, the blood pressure in all four extremities, venous pressure, vital capacity, circulation time by means of decholin, carbon dioxide inhalation, and Mascosol, electrocardiograms and $x$-rays of the chest (Tables I and II). Clinical observations of five other patients are included in Table I.

2. The heart at rest was found to maintain a normal or even increased volume output of blood in coarctation of the aorta before the onset of failure. In only one of the nine cases was the cardiac output decreased (Case 9). In only one of these patients (Case 4) was the heart enlarged to give a cardiothoracic ratio greater than 50 per cent. The work of the heart in relation to the cardiac size was, as a consequence, adequate in all except this one case (Case 4). This patient had a cardiac output within normal limits but it was not in proportion to the greatly enlarged heart.

3. The systolic blood pressure in the arms was higher than that in the legs in all except one patient. This finding was the most constant of the characteristic signs of coarctation of the aorta. In most cases, there was not only an increase in the resistance to the outflow of blood at the site of coarctation and in the collateral channels, but also a generalized increase in peripheral resistance sufficient to maintain a high diastolic pressure below the level of the coarctation.

4. The circulation time was within or near normal limits above the level of coarctation but there was a tendency to prolongation below the coarctation.

5. Erosion of the inferior margins of the ribs posteriorly, giving rise to scalloping and notching, was the most common $x$-ray finding in coarctation of the aorta. This was noted in eleven of the fourteen cases.

6. Enlargement of the heart and T-wave changes in the electrocardiogram point to poor prognosis when they occur.

\section{BIBLIOGRAPHY}

1. Blumgart, H. L., Lawrence, J. S., and Ernstene, A. C., The dynamics of the circulation in coarctation (stenosis of the isthmus) of the aorta of the adult type, relation to essential hypertension. Arch. Int. Med., 1931, 47, 806.

2. Grollman, A., and Ferrigan, J. P., Jr., Cardiac output; its related functions in a case of coarctation of the aorta. Arch. Int. Med., 1934, 53, 35.

3. Strayhorn, W. D., Coarctation of the aorta: a case report with observations on the cardiac output during and after pregnancy. M. Papers Christian, Birthday Vol., 1936, 134.

4. Stewart, H. J., and others, The effect of valvular heart disease on the dynamics of the circulation; observations before, during and after occurrence of heart failure. Am. Heart J., 1938, 16, 477.

5. Lequime, J., Le debet cardiaque; etudes expérimentales et cliniques. Acta med. Scandinav., 1940, Supp. 107.

6. Grollman, A., The cardiac output of man in health and disease, Charles C. Thomas, Springfield, Illinois, 1932, p. 73.

7. Grollman, A., and others, Studies in congestive heart failure. XXIII. A critical study of methods for determining the cardiac output in patients with cardiac disease. J. Clin. Invest., 1933, 12, 751.

8. Stewart, H. J., and Bailey, R. L., Jr., The effect of unilateral spontaneous pneumothorax on the circulation in man. J. Clin. Invest., 1940, 19, 321.

9. Standardization of precordial leads. Joint recommendations of American Heart Association and Cardiac Society of Great Britain and Ireland. Am. Heart J., 1938, 15, 107.

10. Taylor, F. A., Thomas, A. B., and Schleiter, H. G., $A$ direct method for the estimation of venous blood pressure. Proc. Soc. Exper. Biol. and Med., 1930, 27, 867. 
11. Levy, R. L., The size of the heart in pneumonia; a teleoroentgenographic study, with observations on the effect of digitalis therapy. Arch. Int. Med., 1923, 32, 359.

12. Bardeen, C. R., Determination of the size of the heart by means of x-rays. Am. J. Anat., 1918, 23, 423.

13. Tarr, L., Oppenheimer, B. S., and Sagar, R. V., The circulation time in various clinical conditions determined by the use of sodium dehydrocholate. Am. Heart J., 1933, 8, 766.

14. Spier, L. C., Wright, I. S., and Saylor, L., A new method for determining the circulation time throughout the vascular system. Am. Heart J., 1936, 12, 511.

15. Gubner, R., Schnur, S., and Crawford, J. H., The use of $\mathrm{CO}_{2}$ inhalation as a test of circulation time. J. Clin. Invest., 1939, 18, 395.

16. Stewart, H. J., and Watson, R. F., The circulation in athletes. J. Clin. Invest., 1940, 19, 35.
17. Nylin, G., The cardiac output of children. Skandinav. Arch. f. Physiol., 1933, 66, 97.

18. Harrison, F. F., Coarctation of the aorta of the adult type, associated with cystic degeneration of the media in the first portion of the arch. Arch. Path., 1939, $27,742$.

19. Stewart, H. J., and others, The cardiac output in congestive heart failure and in organic heart disease. Ann. Int. Med., 1940, 13, 2323.

20. Woodbury, R. A., Murphey, E. E., and Hamilton, W. F., Blood pressures in aortic coarctation. Study of pulse contours taken by the direct method. Arch. Int. Med., 1940, 65, 752.

21. King, J. T., The blood pressure in stenosis at the isthmus (coarctation) of the aorta; case reports. Ann. Int. Med., 1937, 10, 1802.

22. Steele, J. M., Evidence for general distribution of peripheral resistance in coarctation of the aorta: Report of three cases. (To be published.) 